\title{
PROVIDE A MODEL TO SELECT PROPER DELIVERY SYSTEM FOR RAILWAY PROJECTS IN IRAN
}

\author{
Kobra Gharouni Jafari \\ School of Management \\ Tehran University \\ Tehran, Iran \\ E-mail: K_gharouni@yahoo.com \\ Esmatullah Noorzai \\ Faculty of Civil Engineering \\ Tehran University \\ Tehran, Iran \\ E-mail: noorzai@ut.ac.ir \\ Seyed Reza Makkiabadi \\ Faculty of Civil Engineering \\ Tehran University \\ Tehran, Iran \\ E-mail: makkiabadi@ut.ac.ir \\ Rouhollah Heshmat Nejad \\ Hadish Company \\ Zahedan, Iran \\ E-mail: hadish.company@yahoo.com
}

\begin{abstract}
Railway construction projects due to extent of dimension and nature of activities related to the preparation, implementation, maintenance and exploitation of these projects and effects from how we execute them and considerable utilization of economic resources are of particular importance and they typically are considered of the most important and influential infrastructure projects in countries such as Iran. Hence making any significant improvement in the construction of railway projects results in significant benefits in national economy. One of the most important and strategic factors in success of infrastructure projects is Delivery System Selection Process. Thus the identification of effective criteria for the selection of a proper delivery system in railway projects is of utmost importance which if properly be selected, proper progress in the implementation of these projects will be reached. The survey purpose is to present a model for choosing a proper delivery system for railway projects. In this paper 15 influential criteria on selection of proper delivery system for railway projects were obtained in three main Delivery Systems: Design and Build (DB), Design-Bid-Build (DBB), and Construction Management $(\mathrm{CM})$ using theoretical studies, questionnaire and personal interview and impact of each criterion on alternatives was measured. Then a model for choosing the optimal delivery system and ranking criteria were designed by AHP technique and


EXPERT CHOICE software that is one of the best methods to choose the delivery system. Finally, to assess the validity of the model, results of model were compared with the actual results of the case studies. The results show that the proper delivery system for railway construction projects in Iran is CM. This research could help contractors, consultants, owners, policy makers, and decision makers working in railway construction projects in selection and proposing appropriate delivery system.

Keywords: delivery system, railway projects, AHP approach, infrastructure, criteria, Design and Build, Design-Bid-Build, Management Construction.

\section{Introduction}

Selecting delivery system is one of the main steps in project strategic management and has an impact directly on Different phases of construction projects including Design, implementation and exploitation and in a case of mistake in delivery system selection, Major challenges in managing these types of projects will rise [1]. The railway construction projects are one of the most important infrastructure projects in the countries. Thus one of the main decision makings in rail projects is correct selection of delivery system that will influence on the design and exploitation directly. In railway projects, various delivery systems such as design - build, design - bid - build and Construction management has been used in Iran and other countries yet. Delivery system selection should be done based on different measures of economic, technical, social and also speed and ease of implementation. Especially in railway construction projects, proper selection of delivery method is of importance very much and cause completion of projects in planned time and cost [2]. This makes it necessary to use a scientific and applicable model for suitable system selection considering effective measures on rail projects. Generally delivery system selection is very complicated due to Uncertainty in decision-making. Knowledge of delivery methods is very wide including diverse specialization but has a poor structure. In recent years the application of multi-criteria decision-making methods (MCDM) in the construction management and engineering has been noted very much. The MCDM method ranks different options based on multiple criteria that often conflict each other. One of the most widely used methods in order to decision-making for delivery system selection is Analytic Hierarchy Process (AHP) method. This decision-making method is established on paired comparisons and judgment of experts [3]. In this paper it is tried to determine the most appropriate delivery system using MCDM method with studying and evaluating various options of delivery systems and specifying effective measures on delivery method selection in rail projects considering Iran conditions. Proper method selection can effectively cause reducing risks related to occupational safety and health, achieving improved quality and higher productivity reducing the cost and time of project implementation and finally arriving to project delivery with stakeholder Satisfaction considering environmental conditions and effective measures on railway construction projects [2].

\section{Literature review}

180 years after starting the rail transportation for passenger and cargo, by comparing with air and road transportation, it has advantages such as high safety, lower fuel consumption, less environmental impact and high Capacity; and as an advanced and environmentally friendly method of transport and a development factor, it is considered

$\begin{aligned} & \text { International Symposium of } \\ & \text { the Analytic Hierarchy }\end{aligned}$
$\begin{aligned} & \text { Process } \\ & \text { Wune 29- July 2, 2014 }\end{aligned}$


yet and is used in the world widely [4]. One of the characteristics of this transportation system is the relative complexity and also its construction and operation requires heavy investment. In recent years, special attention has been paid to the development of rail transport and railway lines in Iran and proper planning has been done by the government to compensate for the backwardness of this sector. Many researches have been done on the railway in the world, but the subject of project delivery systems and using scientific methods in the selection of project delivery method has been considered less. Then types of delivery systems usable in railway projects and decision-making methods will be discussed.

\subsection{Delivery systems}

Delivery systems (construction contracts) are classified into three main groups including Design - Build (DB), Design - Bid - Build (DBB) and Construction Management (CM) that each group has several subsets $[5,6]$. In DBB method project is financed by owner and design and build are provided separately by separate sources outside employer. As a result, in this type of delivery system, the owner firstly provides project design from outside source or sources and then assigns project construction to other external source or sources. Obviously, in this system responsibility and the risk of coordination between design, construction, management and project control are carried out by owner. The project in this system is followed sequentially. It means that contractor is selected after completion of design and fulfillment of bid documents. In this structure, the employer has a contractual relationship the consultant and the contractor. The owner chooses the consultant as a representative to design and monitor project implementation in accordance with the contract documents and technical specifications required by the employer [7]. In DB method, the owner firstly identifies and assesses own capacities of internal enterprise, after this a contract is signed with a unique nature to provide project (or at least the final second phase) and project implementation. Contract might be signed with a single designer-constructor in negotiations or by obtaining competitive bids. Selection of designer-constructor can be done based on just lower price or Combination of valuation criteria and specific factors such as similar experiences in projects, experiments and key labor capacities, equipment and other factors that be considered together [6]. CM system is formed based on the agreement between the employer and approved Construction Company and based on this agreement, the company is committed to handle project within the determined range of services, leadership and management [5]. The main variable in this system is the amount of risk that construction manager takes over during services. So CM system is classified to two main groups: CM as an employer representative and $\mathrm{CM}$ at risk. In $\mathrm{CM}$ as an employer representative, Construction Company takes over the role of employer representative - of course, the parallel relationship with designer or project engineer- and manages other institutions involved in the project from the beginning of the work. In CM at risk, Construction Company is considered as a project builder and acts more like a general contractor of the project in implementation phase. This kind of agreements of $\mathrm{CM}$ can be prepared considering special articles which explain how to provide services to owner by design and construction teams. However these two types of agreements of construction management have compatibility with most of the projects [8]. 


\subsection{Decision making methods}

Diverse methods can be used for selecting the best delivery system in rail projects using decision making. These methods are divided to two main groups in various procedures in the field of Multi-trait models in Literature, including Non-Compensatory models and Compensatory models [9].

In Non-Compensatory models exchange between the criteria is not valid; it means the disadvantage of a measure is not compensated by the advantage of the other criteria. In Non-Compensatory models exchange between the criteria is not valid; it means the disadvantage of a measure is not compensated by the advantage of the other criteria. Therefore, any measure is singly proposed in this method and comparisons are done based on measure to measure; whereas in compensatory models exchange between the criteria is valid. It means a change (probably small) in a measure can be countervailed by an opposite change in the other criterion (or criteria).

MCDM methods are one of operation research parts which have had rapid growth in the past two decades. A number of tangible options are ranked based on multiple criteria from the best to the worst by these methods. This approach considers theory and methodology of complex issues in management, business, engineering and other fields of human activities [10].

In general, most of the selection methods are divided into three main stages. In different methods, these items vary: Each of these stages to what extent is numerical and mathematical and to what extent is based on expert judgment or expert judgments during what process lead to quantitative results. But all of the methods have more or less of these three steps, generally:

- Determining options ahead and recognizing them

- Identifying evaluation criteria and indexes and weighting them

- Scoring options based on criteria and indexes considering their weighting score and choosing best option

One of the most efficient MCDM methods is Analytic Hierarchy Process (AHP) which was introduced for the first time by Tomas L. Saaty in 1970. This technique is based on paired comparisons and gives to managers the opportunity to evaluate different scenarios [11].

In consideration of simple nature and yet comprehensive of this process, it has been welcomed by leaders and different users in the scientific community. AHP process makes possible the combination of qualitative criteria along with quantitative criteria simultaneously. This process is based on paired or pair-wise comparisons of the options and criteria of decision making. For such a comparison it would be required to collect information from the decision makers. This makes the decision maker able to focus only on comparing two criteria regardless of any external influence or interference. Moreover, the pair-wise comparison provides valuable information to investigate the problem under study and makes the decision making process rational because the participants compares just two factors and has no attention to the other ones. Having examined the information provided in the filled questionnaires, accuracy of the information should be checked with an Incompatibility Rate (IR) that should be less than 0.1 , is calculated by software [12]. It can be said that analytic hierarchy is one of the most comprehensive systems for multicriteria decision making and has the ability to formulate the problems in terms of 
qualitative and quantitative criteria based on the paired comparison. It provides the possibility for a sensitivity analysis on all the criteria and sub-criteria. It will also demonstrate the compatibility/incompatibility rate of the decision as one the most important features of this technique in the multi-criteria decision making based on axioms [11].

\section{Research background}

Vladimir Ozernoy (1988) argued that an expert system can be designed to help the decision-makers for choosing proper MCDM method in terms of a given problem. Saying MCDM method selection is a MCDM problem, he supposes that the user has a preset list of available methods and purposes to choose the best of them for exertion in his problem. In this paper, a conceptual framework is created for an expert system and targets, structures and possible applications of this system are expressed [13].

Guitoun and Martel (1988) stated that there are various decision making methods and none of them are recognized as a preferred method in all conditions. Thus they tried to answer this question that how we can find proper decision making method for a specific and imposed problem and finally they presented a conceptual framework with seven preliminary guides for selecting proper decision making method [14].

Wong et al. (2007) ranked construction systems using AHP method in view of the Constructability criterion in Hong Kong [15].

Kristo Mela, Teemu Tiainen and Markku Heinisuo (2012) exerted several methods of decision making in building design to study the efficiency and their results. Six methods are compared including: weighted sum, produced sum, VIKOR, TOPSIS, PROMETHE II and a procedure based on PEG-theorem. In this paper, the best MCDM method was not determined but the performance of each method was explained [16].

Ishizaka and Labib (2011) reviewed accomplished developments in AHP method since its creation. Their study was more concentrated on methodologic Developments instead of AHP application. The important AHP areas were discussed such as paired comparisons, judgment scales, joinder indexes, weights combination, sensitivity analysis etc. Finally, they said that although some decision methods are more accurate, complicated and intangible and it should be balanced between the hale model and usability model, however they knew AHP method as a suitable method that is applicable in many items from the past to the present [17].

Ali Jahan et al. (2011) worked on selection of materials. Because choosing the material is a complicated problem like the building method selection, MCDM methods are valuable tools. Using different MCDM methods lead to different results and rankings of options. They presented a method named aggregation technique in which the input is different obtained ranks of each option in different MCDM methods and the output is new ranking of options [18].

Al Khalil (2002) suggested a model based on Analytic Hierarchy for optimal selection of delivery system. In consideration of three main criteria and detailing more these criteria, he did final selection between three possible options including design - build, design bid - build and Construction management systems. Al Khalil believed that AHP was an efficient method for decision making related to project delivery system due to its ability to incorporate "tangible and intangible factors" and the possibility of breaking down the problem into AHP hierarchies [19]. 
Mafakheri et al (2007) preferred AHP over other methods of decision making and developed a list of criteria which were used by the owners when evaluating the delivery methods [20].

Wang et al (2009) used a combination of Fuzzy hierarchical TOPSIS method for choosing the supplier and concluded that they would be unsuccessful for modeling uncertainties of the projects [21].

Ghavamifar (2009) found analytic hierarchy as an effective way to assist the decision maker for breaking down the complex problems into much simpler ones. He proposed a model in the context of selecting the optimal delivery system for the projects and faced the owner with two basic questions: First question was that could the PPP method be used and if the answer was negative, then the second question raised that deals with choosing the best option among the three possible options. In other words, the delivery system should be selected based on greater scores by using AHP method and expert systems out of the following options: Design-Build, Design-Bid-Build methods and construction management [22].

Transit Cooperative Research Program (TCRP) (2009) published a Guidebook for the Evaluation of Project Delivery Methods in order to introduce the analytic hierarchy technique as a suitable method for choosing the delivery system [23].

Transformation research centre in Iran (2013) identified the best delivery system for railway construction projects in Iran using AHP method [24].

\section{Research method}

At this stage, it was tried to determine the most effective factors affecting selection of the optimal delivery system through interviews with experts and by using a multi-criteria decision making method of analytic hierarchy process.

Generally speaking, two original questionnaires were used in this research work: The first questionnaire determines the factors affecting the railway projects, while the second one examines the effects of each factor on the delivery system, then the results were analyzed using AHP process.

The striking challenges of the delivery systems in the rail construction projects were categorized within the scope of this research and then, the significance of these challenges were addressed according to the numerical scale of table 1 . This scale shows paired oral judgment and was introduced for the first time by Saaty.

Table 1- Preferences (Oral judgment)

\begin{tabular}{|l|c|}
\hline Extreme importance & 9 \\
\hline Very strong and demonstrated importance & 7 \\
\hline Strong importance & 5 \\
\hline Moderate importance of one over another & 3 \\
\hline Equal importance & 1 \\
\hline Intermediate values between adjacent scale values & $8,6,4,2$ \\
\hline
\end{tabular}

\subsection{Effective factors affecting selection of the delivery system in rail projects}

The first questionnaire which was basically designed to show how significant each criterion is from experts' point of view extracted 15 important criteria in the rail construction projects as below: 
- reduction of project cost

- reduction of project time

- improvement of project quality

- reduction of owner's risks

- existence of a single responsibility between design and construction

- minimum number of project claims and contractual conflicts

- project flexibility against changes during construction period

- bureaucracy

- error in estimating project final cost

- definite project finance

- national economic situation

- project size

- legal considerations/limitations and related regulations

- Efficient and defined mechanisms for accurate reception and analysis of information related to project

- Project return

\subsection{Delivery system options}

The options which are considered in this study for delivery system selection in rail projects are listed as follows:

- $\quad$ Design - Build (DB)

- $\quad$ Design - Bid - Build (DBB)

- Construction Management (CM)

\subsection{Data survey}

Some 42 questionnaires had been sent to the participants from which 40 questionnaires were returned. At this stage, after gathering questionnaire number 2, at first the effect of each of 15 factors on each delivery system is determined and then all criteria are compared each other in pairs. After that the results are analyzed using AHP method and the score of each delivery system and the importance of the factors are determined and finally systems and factors are categorized and arranged based on the highest obtained score. An example of a completed questionnaire is illustrated in table 2 which belongs to the comparison between 15 criteria for selection of the optimal delivery system in the rail construction projects. If the "reduction of project cost" criterion, for instance, is a little more important than the "national economic situation", then a number 3 will enter into the matrix, whereas if importance of the "improvement of project quality" criterion is a little more than "reduction of project cost", then a value of $1 / 3$ will be entered; and this is how the table should be filled. Ultimately, the Inconsistency Ratio (IR) of the questionnaire is found to be 0.06 that is less than 0.1 . Thus, it can be argued that data of the questionnaire are reliable. 
IJAHP Article: Mu, Saaty/A Style Guide for Paper Proposals To Be Submitted to the International Symposium of the Analytic Hierarchy Process 2014, Washington D.C., U.S.A.

Table 2- Completed questionnaire

\begin{tabular}{|c|c|c|c|c|c|c|c|c|c|c|c|c|c|c|c|}
\hline & 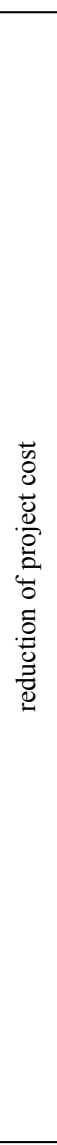 & 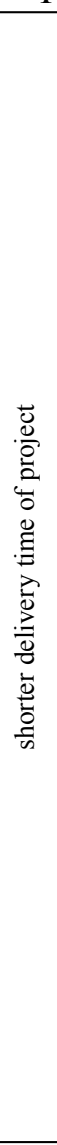 & 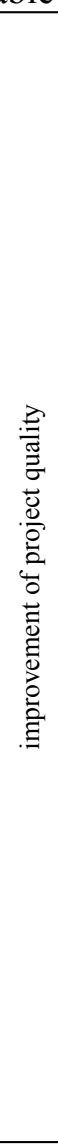 & 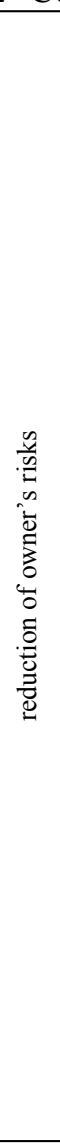 & 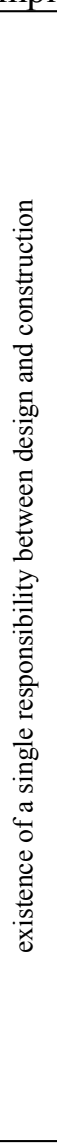 & 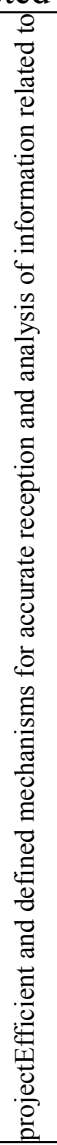 & 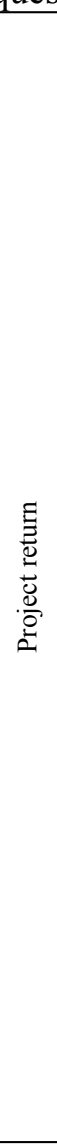 & 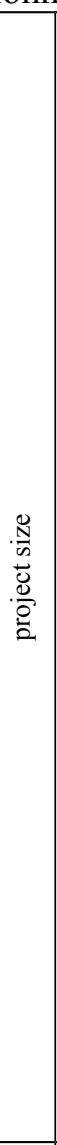 & 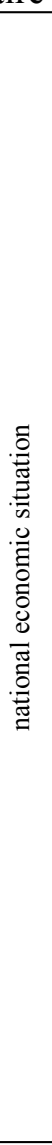 & 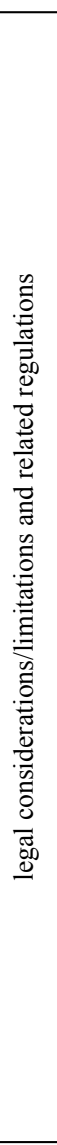 & 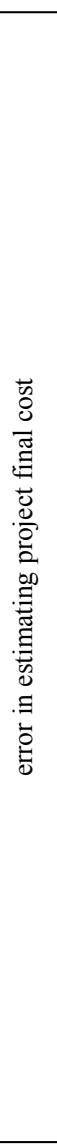 & 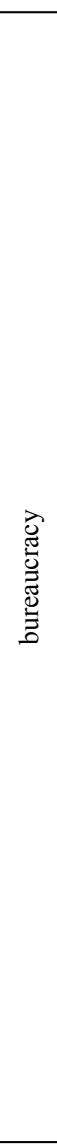 & 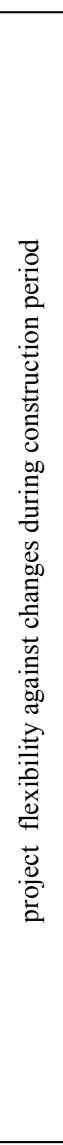 & 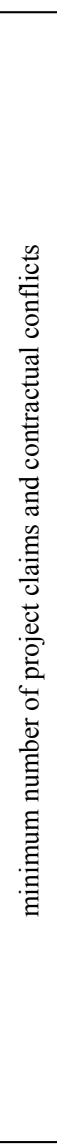 & 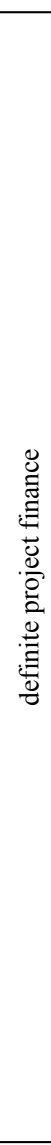 \\
\hline reduction of project cost & 1 & 1 & $1 / 3$ & 1 & 3 & 1 & $1 / 5$ & 5 & 3 & 1 & 1 & 3 & 1 & 3 & 2 \\
\hline $\begin{array}{c}\text { shorter delivery time of } \\
\text { project }\end{array}$ & & 1 & $1 / 5$ & 1 & 3 & 3 & $1 / 5$ & 3 & 5 & 3 & 1 & 5 & 3 & 3 & 3 \\
\hline $\begin{array}{c}\text { improvement of project } \\
\text { quality }\end{array}$ & & & 1 & 3 & 5 & 5 & 1 & 5 & 5 & 7 & 3 & 7 & 4 & 7 & 3 \\
\hline reduction of owner's risks & & & & 1 & 3 & 3 & $1 / 5$ & 5 & 7 & 3 & 3 & 5 & 3 & 3 & 2 \\
\hline $\begin{array}{l}\text { existence of a single } \\
\text { responsibility between } \\
\text { design and construction }\end{array}$ & & & & & 1 & 1 & $1 / 5$ & 3 & 3 & 1 & 1 & 3 & $1 / 2$ & 1 & 1 \\
\hline $\begin{array}{l}\text { Efficient and defined } \\
\text { mechanisms for accurate } \\
\text { reception and analysis of } \\
\text { information related to } \\
\text { project }\end{array}$ & & & & & & 1 & $1 / 5$ & 3 & 3 & 1 & 1 & 1 & 3 & 1 & 1 \\
\hline Project return & & & & & & & 1 & 5 & 5 & 7 & 3 & 4 & 7 & 5 & 3 \\
\hline project size & & & & & & & & 1 & 1 & 3 & $1 / 3$ & $1 / 3$ & 1 & $1 / 5$ & $1 / 3$ \\
\hline $\begin{array}{c}\text { national economic } \\
\text { situation }\end{array}$ & & & & & & & & & 1 & 2 & $1 / 5$ & $1 / 2$ & $1 / 4$ & $1 / 4$ & $1 / 5$ \\
\hline $\begin{array}{l}\text { International Sympos } \\
\text { the Analytic Hierarch } \\
\text { Process }\end{array}$ & 4 & & & & & 8 & & & & & \multicolumn{5}{|c|}{$\begin{array}{l}\text { Washington, D. C. } \\
\text { June } 29 \text { - July 2, } 2014\end{array}$} \\
\hline
\end{tabular}




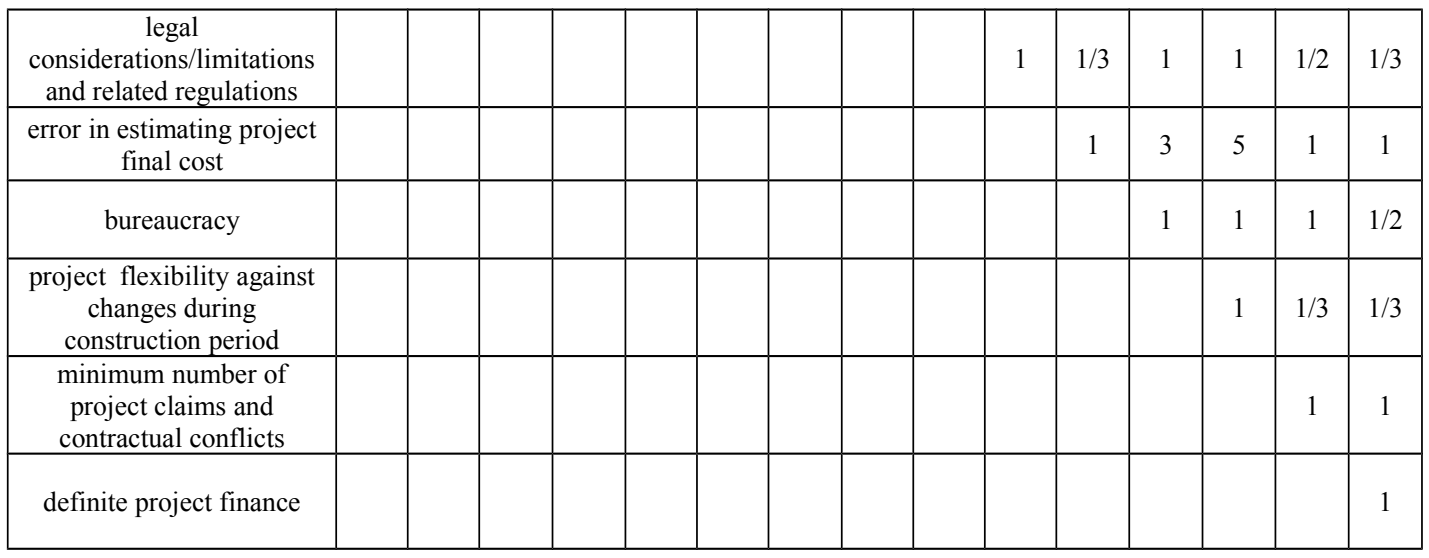

\subsection{Determining the importance of factors and choosing preferred option}

At this stage of the investigation, the importance of the effective factors on delivery system selection in Iran rail projects is obtained using AHP method and Expert Choice software and based on obtained weight. After applying the ideal synthesis, the weights of criteria are divided to the weights of options and thus sum of relative weight of options for each criterion equals the weight of that criterion that shows the weight of three options (Design-Build, Design-BidBuild, Construction Management) considering obtained criterion in rail projects. The numbers in the figure 1 show the rank of each option.

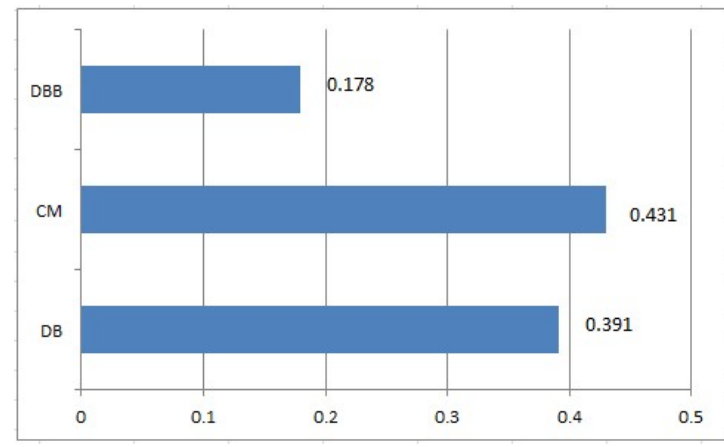

Figure 1- Results of ideal synthesizing for railway projects in Iran (summery)

Also it can be seen the importance of factors affecting selection of delivery system for railway projects in Iran based on obtained weights in figure 2. 


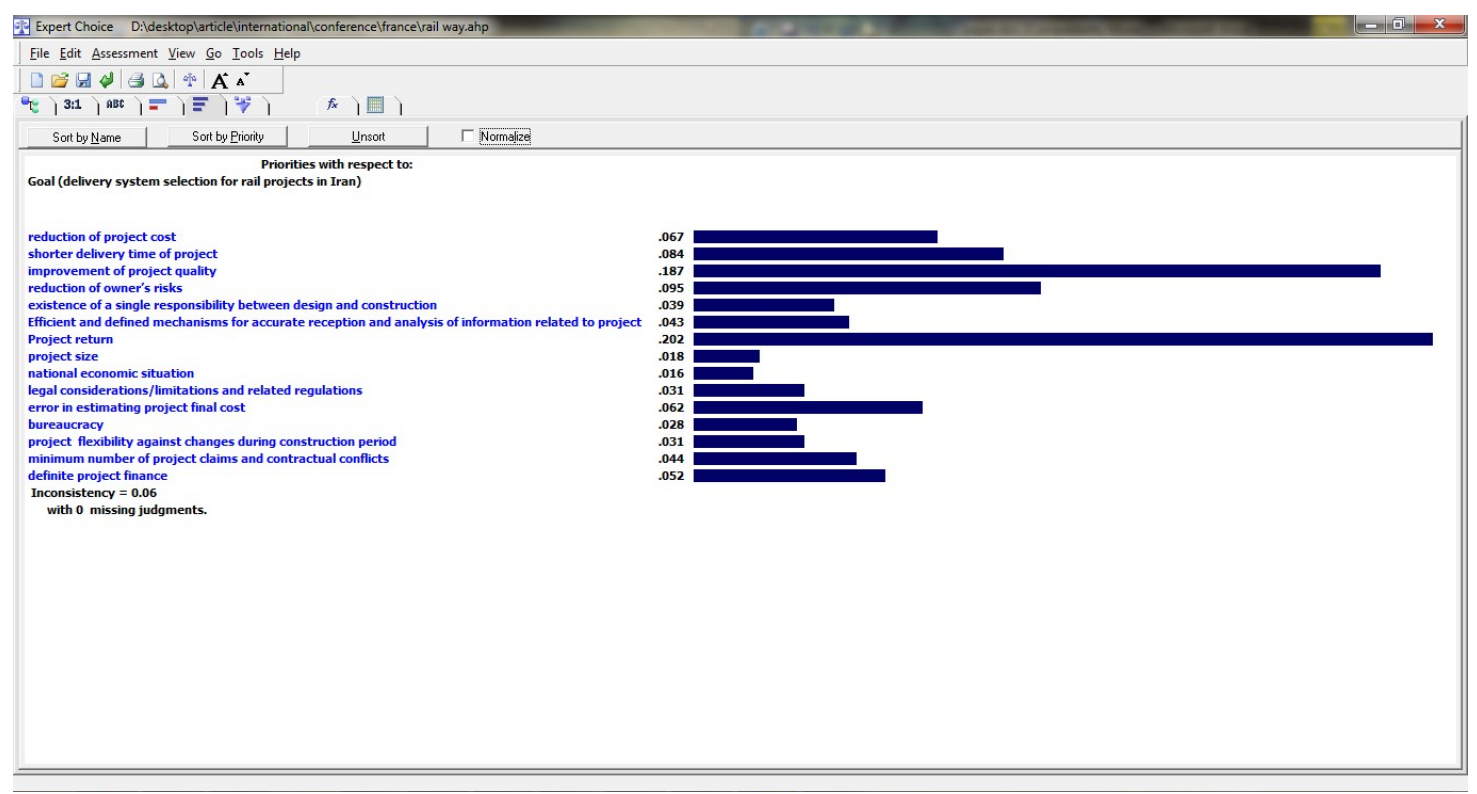

Figure 2- the importance of factors in delivery system selection for Iran rail projects

\subsection{Sensitivity analysis of criteria}

Drawing one-dimensional charts of sensitivity analysis, the results can be more understandable. This figure shows the effect of each factor on each option (delivery system). Using this figure, it can be seen the change of the selected option with the change of each factor from $\% 0$ to $\% 100$. For example in figure 3 , with a little increase in the numerical value of the fifth criterion (existence of a single responsibility between design and construction) DB system will be selected instead of CM system. 


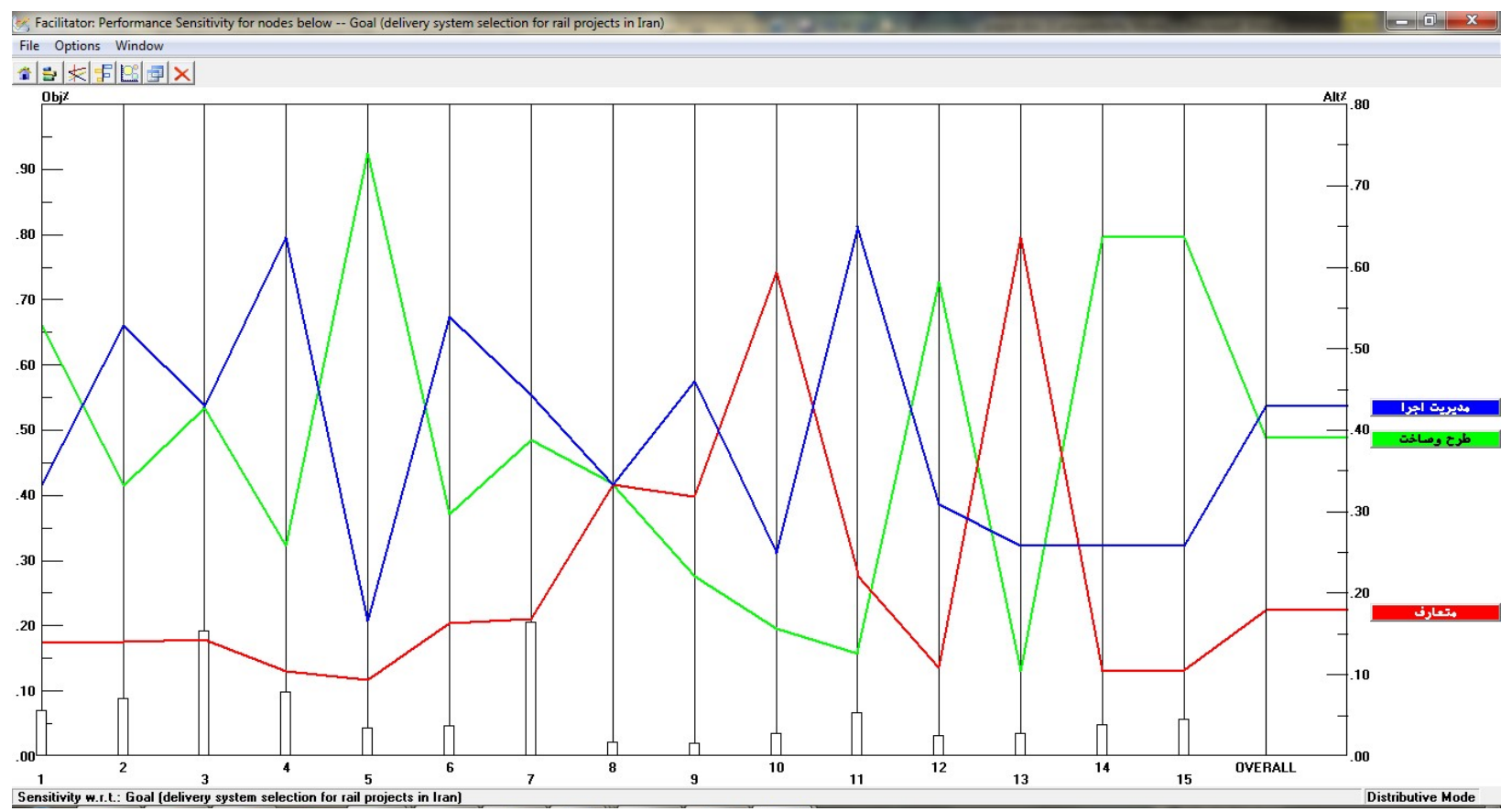

Figure 3- sensitivity analysis of criteria

\section{Results}

Since no project delivery system can be proposed as the best solution absolutely, the most appropriate method for system delivery must be determined based on the conditions of that special project. In other words the owner should recognize the specific conditions and needs of the project to choose a delivery system which guarantees the best ultimate outcomes.

It is obvious that each of the project delivery systems has their own advantages and disadvantages. Therefore, at the time of selecting the project delivery system, the owner should explore a method that causes the greatest value for the money spent. For this purpose, the owner must first identify different potential approaches of the project delivery systems with the specifications for each of them carefully and then, determine the specific conditions of the project as well as the available capabilities.

In this regard, the most effective criteria for decision making to select the optimal delivery system of the rail construction projects were identified through some questionnaires. Then the different options of delivery systems including Design-Build, Design-Bid-Build for rail projects was determined. The reliability of questionnaire was calculated using Cronbach's Alpha and SPSS software, which yielded a parameter of 0.92 magnitude. In the following, AHP methodology and Expert choice software were utilized to select the optimal delivery system for Iranian rail construction projects. In this examination and applying all the identified criteria, the most appropriate method of delivery system for the rail construction projects in Iran was found the CM method with 0.431 points and after that the DB system with 0.391 points had the second ranking. Eventually, the third item was the DBB having 0.178 points. The DBB method is currently the dominant method used in Iran, though this study suggests that it's better to 
use CM method instead of DBB method. According to the results of this research, it can be declared that the DB method is not recommended for the rail construction projects in Iran. Also, it is showed the importance of each criterion in decision making process with the sensitivity analysis

\section{Conclusion}

Selection of the project delivery system is described as a unique process in most of the literatures. However, a scientific and step by step investigation of different selection steps of the delivery system as well as taking into account and studying their key points in the road construction projects are of major importance. Furthermore, in most cases the process of choosing the delivery system in these projects and the effective factors on them are rather general and theoretical, so that they have studied these challenges to a limited extent in terms of executive issues, and viewpoints of local experts and all involved parties. At the same time, it is possible that these challenges change any time with any condition.

The main advantages of this study include:

- Identification of the challenges in terms of the executive issues, and the local experts and parties involved in the delivery systems ;

- Identification of the practical challenges due to using the viewpoints of local experts and parties involved in the delivery systems in Iran;

- Determination of the optimal delivery system for the road construction projects with respect to Iran's current conditions in terms of the executive issues, and the viewpoints of local experts and parties engaged in the delivery systems in Iran;

- Using AHP method and Expert Choice Software for selecting the optimal delivery system for the road construction projects which is one of the most appropriate methods for selection of the delivery system;

- Paying attention to the key points for the delivery systems during the research and keeping the identified factors up to date;

- Assessment of research validity and reliability by using SPSS Software.

\section{References}

[1] K. Taghizade, E. Noorzai, K. Gharouni Jafari, "Identifying the main challenges of current delivery systems in Iran", The 6th International Project Management Conference, Tehran, Iran, Jan. 2011

[2] E. Noorzai, K. Gharouni Jafari, B. Farhang Moghadam, B. Vahedi, "Optimal selection of Iran rail projects private partnership financing method using AHP method", The 6th Civil Engineering Conference in Asia Region (CECAR6), June 2013

[3] T. L. Saaty, L. G. Vargas, "Models, Methods, Concepts and Applications of the Analytic Hierarchy Process", Kluwer Academic Publishers, Boston, 2000

[4] S.R. Makki abadi, E. Noorzai, S.M. Afzali, "Public Private Partnership (PPP) in High Speed Rail projects in the World, Survey on Challenges and Obtained Experiences", The third International Conference on Recent Advances in Railway Engineering (ICRARE 2013), May 2013 
IJAHP Article: Mu, Saaty/A Style Guide for Paper Proposals To Be Submitted to the International Symposium of the Analytic Hierarchy Process 2014, Washington D.C., U.S.A.

[5] R. W. Dorsey, "Project Delivery System for Building Construction" Associated General Contractors of America, Arlington, 87-92, 1997

[6] American Society of Civil Engineers (ASCE), "Quality in the constructed project: a guide for owners, designers, and Constructors", CHAPTER 3, 2000.

[7] Iran's management and planning organization. "Study and investigation of various delivery methods" Third chapter, Tehran, Iran, 2006

[8] K. Rasooli, "Key areas of improvement and development of contract sets of project management (MC)", The Third International Project Management Conference, 2006

[9] M. J. Asghar poor, "multi-criteria decision making", Third Edition, Tehran, Tehran University Press, 2004

[10] A. Azar, A. Rajab Zadeh, "practical decision making with MADM approach", Tehran, Negah-e-Danesh, 2010

[11] R.W. Saaty, "Decision Making for Leaders; the Analytical Hierarchy Process for Decisions in a Complex World", RWS Publications, 4922 Ellsworth Ave., Pittsburgh, PA 15213, 2000.

[12] I. M. Mahdi, K. Alreshaid, "Decision support system for selecting the project delivery method using analytical hierarchy process (AHP)", International Journal of Project Management, 2005.

[13] V. M. Ozernoy, "Some issues in designing an expert system for multiple criteria decision making", 1988

[14] A. Guitouni, J.-M. Martel, "Tentative guidelines to help choosing an appropriate MCDA method", European Journal of Operational Research, 1998

[15] P. T. I. Lam, A. P. C. Chan, F. K. W. Wong, F. W. H. Wong, "Constructability Rankings of Construction Systems Based on the Analytical Hierarchy Process." JOURNAL OF ARCHITECTURAL ENGINEERING C ASCE, DOI: 10.1061/ (ASCE)1076-0431(2007)13:1(36), 2007

[16] K. Mela, T. Tiainen, M. Heinisuo. "Comparative study of multiple criteria decision making methods for building design", Advanced Engineering Informatics, 2012

[17] A. Ishizaka, A. Labib "Review of the main developments in the analytic hierarchy process", Expert Systems with Applications, 2011

[18] A. Jahan, Md Y. Ismail, S. Shuib, D. Norfazidah, K.L. Edwards, "An aggregation technique for optimal decision-making in materials selection", Materials and Design 32 (2011) 4918-4924, 2011 Elsevier Ltd, 2011

[19] M. Al-Khalil, "Selecting the Appropriate Project Delivery Method Using AHP", International Journal of Project Management, 20(6), 469-474, 2002.

[20] F. Mafakheri, L. Dai, D. Slezak, F. Nasiri, "Project Delivery System Selection under Uncertainty: Multicriteria Multilevel Decision Aid Model”, Journal of Construction Engineering and Management, 23(4). 200-206, 2007.

[21] J.-W. Wang, C.-H. Cheng, K.-C. Huang, "Fuzzy hierarchical TOPSIS for supplier selection" Journal of Applied Soft Computing, 9(1), 377-386, 2009.

[22] K. Ghavamifar, "A decision support system for project delivery method selection in the transit industry", Doctoral Dissertation in Civil Engineering, Northeastern University, Boston, Massachusetts, Paper 7, 2009. http://hdl.handle.net/2047/d20000046

[23] Transit Cooperative Research Program (TCRP), "A Guidebook for the Evaluation of Project Delivery Methods", Report 131, Transportation Research Board Of The National Academics, Washington, D.C., united states, 2009

International Symposium of 13

the Analytic Hierarchy

Washington, D. C.

Process

June 29 - July 2, 2014 
IJAHP Article: Mu, Saaty/A Style Guide for Paper Proposals To Be Submitted to the International Symposium of the Analytic Hierarchy Process 2014, Washington D.C., U.S.A.

[24] Transformation research center, Ministry of road and urbanism, "Selection procedure of type of contracts in construction projects of highway, freeway and railway in corporation of construction and development of national transportation infrastructures", Executive: E. Noorzai, A. A. Najafi, B. Vahedi, Tehran, Iran, 2011 